\title{
Artelogie
}

artelogie Recherche sur les arts, le patrimoine et la littérature de l'Amérique latine

$6 \mid 2014$

Horizons et dispositifs des arts plastiques des pays du Río de la Plata (XXe siècle)

\section{León Ferrari: a inferência do deslocamento geográfico na potência de um ato criativo}

\section{Caroliny Pereira}

\section{(2) OpenEdition \\ Journals}

Edição electrónica

URL: http://journals.openedition.org/artelogie/1275

DOI: $10.4000 /$ artelogie. 1275

ISSN: 2115-6395

Editora

Association ESCAL

Refêrencia eletrónica

Caroliny Pereira, «León Ferrari: a inferência do deslocamento geográfico na potência de um ato criativo », Artelogie [Online], 6 | 2014, posto online no dia 24 junho 2014, consultado o 05 maio 2019 URL : http://journals.openedition.org/artelogie/1275; DOI : 10.4000/artelogie.1275

Este documento foi criado de forma automática no dia 5 Maio 2019

Association ESCAL 


\title{
León Ferrari: a inferência do deslocamento geográfico na potência de um ato criativo
}

\author{
Caroliny Pereira
}

Lançamo-nos, arriscamos uma improvisação. Mas improvisar é ir ao encontro do Mundo, ou confundir-se com ele.

(DELEUZE, 1997: 117)

\section{Introdução}

1 As interferências externas atravessam a subjetivação do artista atuando como uma zona cinza, potente de criação, na qual está aberta e maleável às suas proposições criativas. 0 contexto histórico, social, afetivo... compõem a paleta de recursos subjetivos com que o artista irá manipular, conjuntamente com os materiais que lhes são acessíveis ao seu processo de criação.

2 A maneira com que cada sujeito lida com essas interferências externas são peculiares a cada um, e isso infere no modo com que esse sujeito agencia suas inquietações interiores e as externaliza diante de sua vivência no mundo. A fisicalidade dos elementos que compõem o ambiente no qual habitamos, tais como: a geografia física e política, a cultura, a história, dentre outros, também são características inerentes a cada lugar e que interferem nos aspectos corporal e psíquico de cada indivíduo, seja ele artista ou não.

No presente artigo, entretanto, estamos interessados em como essa relação com o ambiente externo e seu deslocamento, mais precisamente nas mudanças de países, sejam elas voluntárias ou não, interferem na maneira com que o artista cria. Abordaremos mais especificamente o deslocamento do artista argentino Léon Ferrari para o Brasil, e alguns de seus trabalhos de arte desenvolvidos em heliografias, produzidos durante o período em que ele ficou exilado no Brasil. 
O interesse nesta investigação está, ainda que colocado de modo implícito, no movimento, movimento este, gerador de um deslocamento para além da espacialidade, capaz desterritorializar a sedimentação e incitar uma alocação rizomática, onde a conexão é feita por pontos, como num desenho de "liga pontos" desconexo, e no qual a linha possível de se traçar é a "linha de errância". A estrada, o percurso do entre lugares.

5 A partir destas colocações, gera-se a seguinte questão: será o movimento de deslocamento geográfico, pertencente à mesma linhagem do movimento interno - de "forças centrífugas" - propulsor da criação? E, que tipo de direcionamento ela favorece ao acionamento desta criação?

6 Paul Klee coloca a questão desse movimento de ativação do sujeito, como parte de uma tensão: "Exercemos um esforço por impulsos para decolar da terra, mas no patamar seguinte nos elevamos realmente acima dela (...) sob o império de força centrífugas que triunfam sobre a gravidade." (KLEE, apud DELEUZE, 1997: 117).

7 A partir desta tensão colocada por Klee, percebe-se que o deslocamento espacial que um artista efetua, por vezes, também desloca o modo como ele se relaciona com o mundo, suas referências, suas paisagens, modificando de maneira contundente a sua criação em arte. Esse trânsito quase sempre permite que o artista amplie não só a sua percepção do mundo, mas também, os seus recursos imagéticos, agindo como ativadores da criação. Isso é perceptível no vasto número de artistas que se exilam temporária ou permanentemente em outros países, alguns cuja cultura se distingue veemente da sua cultura de origem, e como isso afeta na produção e criação de seus trabalhos em arte.

\section{O deslocamento de León Ferrari para o Brasil}

8 León Ferrari (1920-2013), artista argentino, nasceu no dia 3 de setembro, em Buenos Aires. Seu pai era arquiteto, pintor e fotógrafo. Apesar de não ter frequentado cursos regulares de arte inicialmente, era inerente à Ferrari uma relação próxima com as artes, através de seu pai e o contexto em que eles viviam.

9 Em 1952, Ferrari se mudou para Florença, em busca de tratamento médico para sua filha, que havia contraído meningite tuberculosa. Em 1953 ele se muda com sua esposa e filha para Roma, e residem no Instituto Ítalo-Argentino. Lá, ele tem os seus primeiros experimentos em cerâmica, com o artesão siciliano Salvatore Meli, e trabalha por um ano como ceramista, no ateliê do escultor Renato Marino Mazzacurati. Em 1954 participa do concurso nacional de cerâmica realizado no Museu Internacional de Cerâmica de Faença, e conhece o pintor e comunista Renato Guttuso, assim como também, o artista Lucio Fontana que com seu apoio participa da X Trienal de Milão, no qual Fontana era jurado.

10 Ferrari regressa à Buenos Aires em 1955. Neste período ele desenvolve suas atividades profissionais como engenheiro e em 1958-59, juntamente com Fernando Birri, realiza o media metragem : A primeira fundação de Buenos Aires, baseado no quadro de Oski (Oscar Conti) e inspirado no texto do alemão Enrico Schmidel, do século XVI. É somente em 1959 que Ferrari irá retomar à escultura, desta vez utilizando o cimento e o gesso.

11 A partir de 1961, Ferrari entra em contato com outros materiais com os quais desenvolverá seus trabalhos em escultura. Passa a trabalhar com arame, aço inox (figura1), bronze, prata, ouro, madeira, paládio, tântalo. Essa característica em trabalhar com diversos materiais e mixed media, irá perpetuar por toda a carreira de Ferrari. 


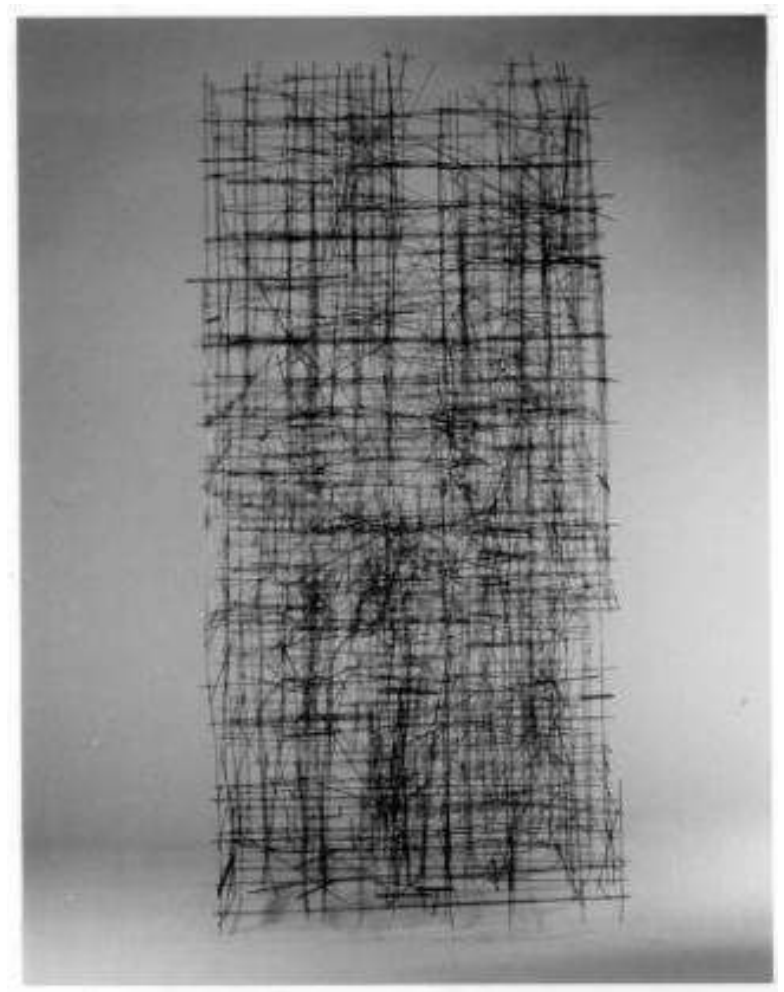

Fonte : http://www.leonferrari.com.ar/index.php?/project/ceramicas-y-maderas-ceramics-woods/

Ressaltar esses fatos biográficos de León Ferrari se faz importante para que possamos evidenciar como os trabalhos em arte - heliografias - produzidos por ele no Brasil podem se relacionar com alguns trabalhos desenvolvidos anteriormente.

Em março de 1976, a Argentina, sob o governo de Isabel Martinéz, sofreu um golpe militar instaurado pela Força Militar e encabeçado pelo general Jorge Rafael Videla, pelo almirante Emilio Massera e pelo brigadeiro Orlando Agostí. Diante deste fato, León Ferrari, que a esta altura já havia um trabalho em arte consolidado e estava bastante engajado politicamente, se exila em São Paulo, no Brasil, com sua família.

Logo que chega ao Brasil, Ferrari retoma a produção de suas esculturas em arame.

\section{A potência criativa de Ferrari no Brasil}

Dentre a vasta gama de trabalhos em arte que Ferrari produziu durante sua morada no Brasil, deter-nos-emos principalmente em suas heliografias, pelo fato de elas abarcarem questões importantes no que concerne ao ambiente - São Paulo - que Ferrari estava inserido.

16 A heliografia - gravura com a luz solar - é um processo fotográfico desenvolvido por Joseph-Nicéphore Niépce (1765 - 1833), inventor francês e responsável pelas primeiras fotografias. Após vários experimentos, Niépce chegou a um processo fotográfico, no qual ele recobria uma placa de estanho com betume branco, este se enrijecia quando entrava em contato com a luz, e nas partes não submetidas a interferência da luz, o betume era 
retirado com uma solução de alfazema. Inicialmente o tempo de fixação das imagens era longo, necessitando de oito horas para a conclusão da gravação da imagem no papel.

A heliografia que fiz e para a qual dei o nome de 'heliografia' consiste na reprodução automática, pela ação da luz, de graduação de tons [que vão] do preto para o branco, de imagens obtidas na câmera escura. (NIÉPCE apud CAVENAGHI, 2008: 9).

17 A primeira heliografia quem ainda resiste ao tempo (figura 2) é datada de 1826 , e foi tirada do quintal da casa de Niépce.

Figura 2: Joseph-Nicéphore Niépce, Sem título (imagem sobre estanho, paisagem da janela da casa de Niépce). 1826

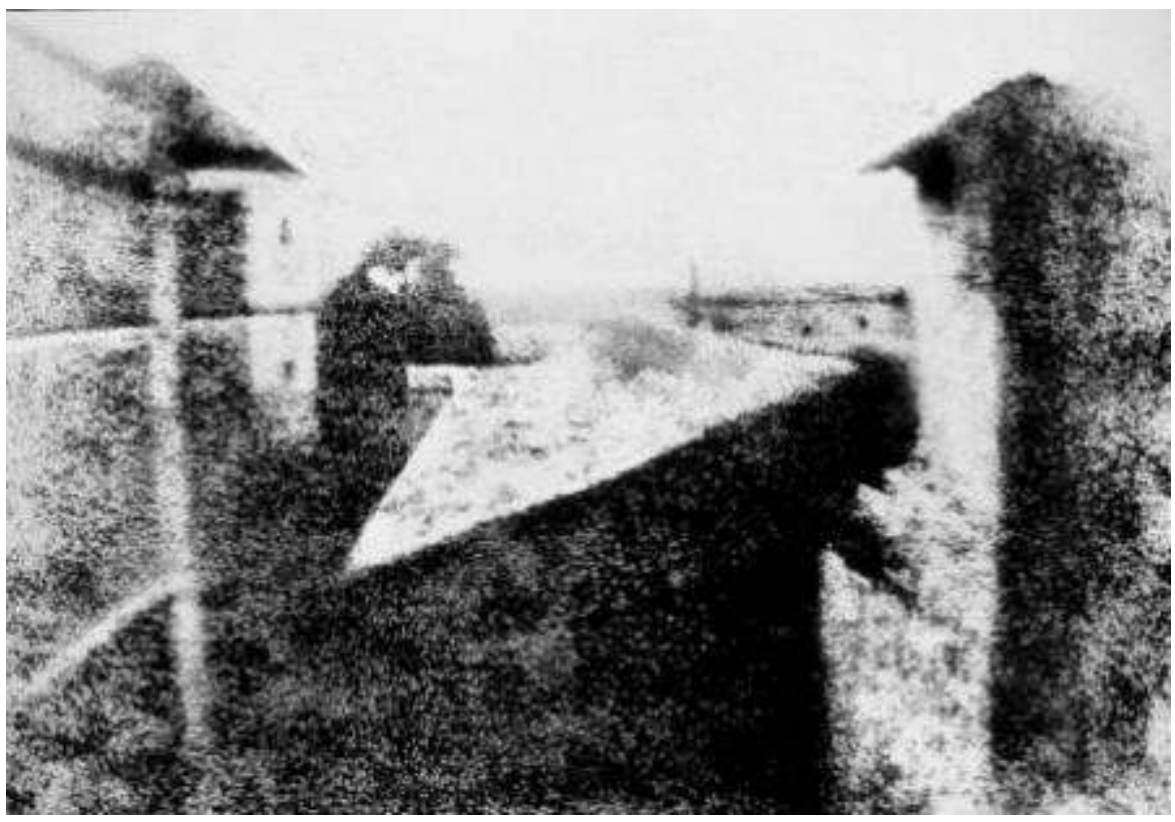

$20,3 \times 25,4 \mathrm{~cm}$. França.

(Reprodução de 1952 : Helmut Gernsheim\& Kodak ResearchLaboratory's, Inglaterra). Fonte : https:// dcl.umn.edu/search/search_r...

18 Quando Ferrari vem para o Brasil, ele conhece diversos artistas, dentre eles, Julio Plaza e Regina Silveira são dois nos quais ele manteve um contato bem próximo e desenvolveram vários experimentos e trabalhos em arte, principalmente em videotextos, microfichas, arte postal, livro de artista.

19 O primeiro contato de Ferrari com Regina Silveira, Julio Plaza, Walter Zanini e Donato Ferrari é no final de 1978, quando ele começou a frequentar o Centro de Estudos Aster, iniciando com Regina Silveira, estudos em litografia. Ali Ferrari também inicia seus trabalhos em fotocópia em papel Fabriano. "O múltiplo, mecanicamente reproduzido, de elevada qualidade visual. Posteriormente seria intitulada de 'Gerox', termo inventado por Julio Plaza, 'síntese' do 'g' de gravura com a palavra 'xerox"'. (AMARAL, $2006: 51$ ).

20 A partir de seus experimentos com relação à reprodução de obras gráficas e fotocópias, Ferrari cria suas primeiras heliografias, desenvolvidas a partir da utilização de letra set, elementos modulares básicos usados na composição de projetos arquitetônicos associados a inscrições gráficas produzidas por ele, são montadas manualmente por ele, e depois são "xerografados" em grandes dimensões e em papéis de boa qualidade, geralmente o vergé. 
21 Há uma articulação sensível entre esses trabalhos em heliografia e suas esculturas produzidas a partir de 1962, em arame, e até mesmo seus desenhos, dada pela relação formal entre eles. O uso de um grafismo sutil, e uma organização composicional que remete a um urbanismo e a uma arquitetura modular, ou mais precisamente à maquetes arquitetônicas, conecta estes três campos de criação.

22 Nas heliografias da série: Arquitetura da loucura - Bairros (figura 4) - essa estrutura modular é disposta de modo a inquirir questões da ordem urbana. É possível efetuar uma relação entre essa disposição e uma incitação e até mesmo um augúrio com relação a um frenético processo de expansão da cidade de São Paulo, e que, assim como os grandes centros urbanos, possuem uma caoticidade peculiar. Em São Paulo, especificamente por seu desenvolvimento ascendente, sem um planejamento prévio adequado, essa caoticidade assume um caráter de fragilidade nesse caos em construção. Em Bairro (figura 4), a precariedade das estruturas que alicerçam o desenho, sugere uma reciprocidade com relação a esse aspecto frágil que um crescimento caótico infere na geografia física e política de São Paulo. De acordo com Amaral:

[...] esses módulos adquirem um caráter peculiar nas mãos de Ferrari, que infunde vida, senso de humor, em ironia fina a seus babilônicos interiores ou às visões impressionantes das multidões de carros em passagens de nível, rodovias, anéis rodoviários, movido evidentemente pela visão urbana caótica, ao mesmo tempo em que excitante e fervilhante, de um grande centro urbano como São Paulo. Nesse fazer manipulando elementos "pré-fabricados" percebia-se que León Ferrari se comprazia na descoberta de um novo meio. (AMARAL, $2006: 53$ ).

Figura 4: León Ferrari, Bairros. 1980

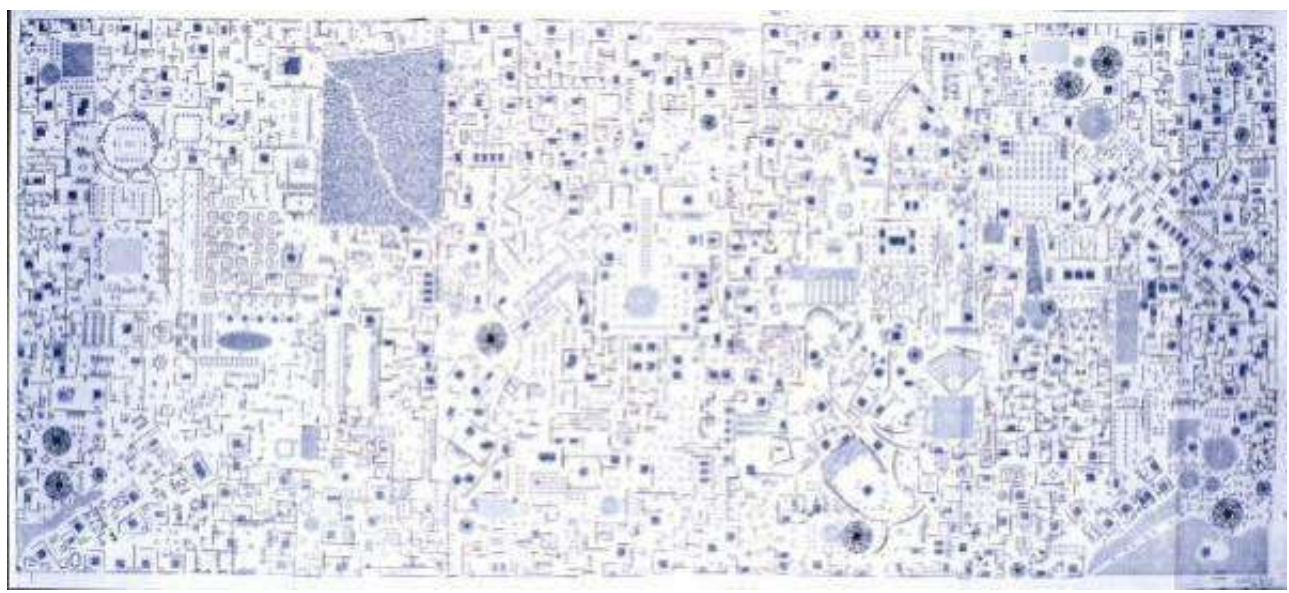

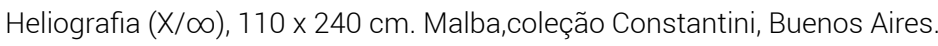

Fonte : http://www.leonferrari.com.ar/index.php?/series/heliografias/ 


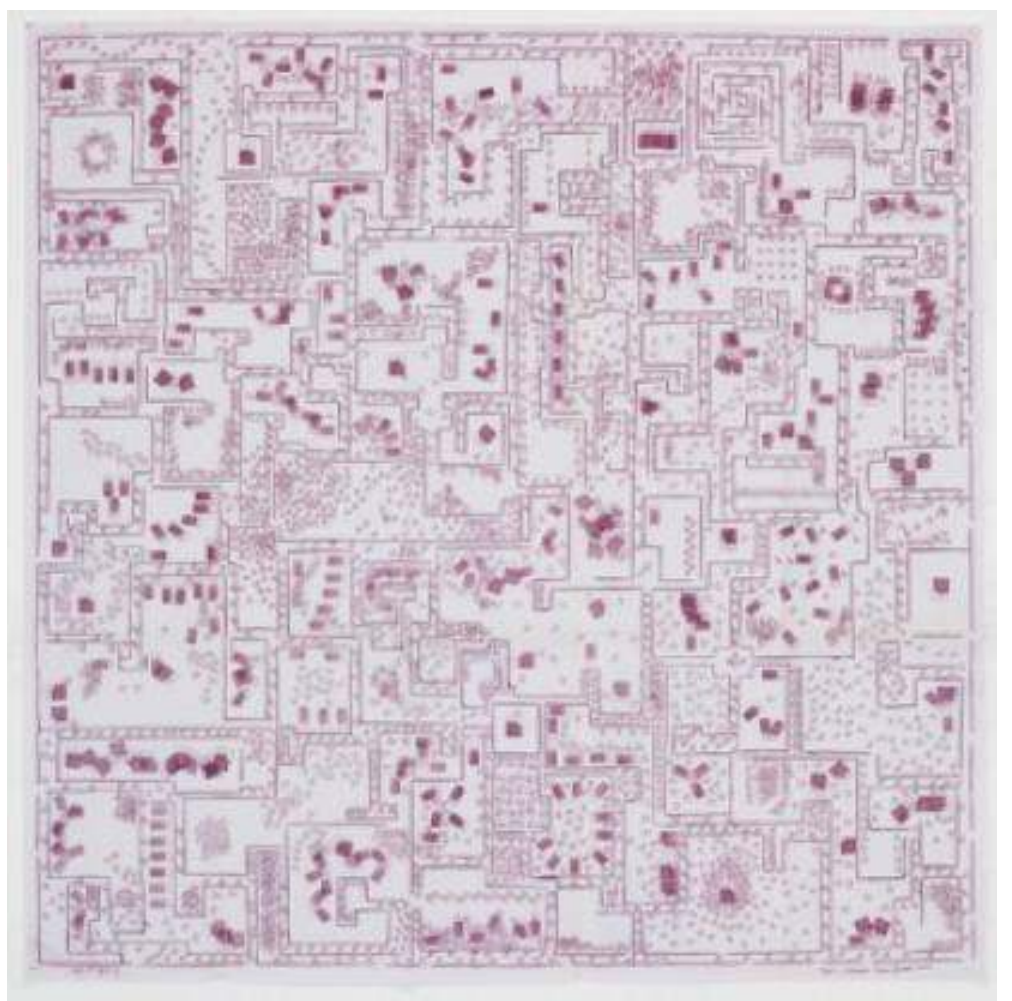

cópia heliográfica. MAM-SP.

Fonte : http://mam.org.br/colecao/acervo/20...

Nas séries heliográficas de Ferrari que incitam esse caráter urbano, e possibilita-nos efetuar uma interlocução com a série do pintor holandês Piet Mondrian (1872 - 1944), não somente pela abordagem do tema "arquitetura urbana", mas principalmente no aspecto formal que ambos conferem à composição de seus trabalhos que se relacionam com estas séries. Mondrian, que também se desloca de seu país de origem, primeiro para França, Inglaterra e depois para os Estados Unidos, vale-se da arquitetura urbana para discutir proposta de análise visual iniciada pelos impressionistas, e que Mondrian consegue avançar. De acordo com o teórico Giulio Carlo Argan, Mondrian tem a intenção de chegar a

[...] uma definição rigorosamente racional do espaço, a qual, porém, não deve se basear em abstrações conceituais, e sim na percepção visual. O terreno de sua pesquisa era, [...] a análise da visão iniciada pelo Impressionismo e levada à frente pelo Cubismo. (ARGAN, 1992 : 351).

Mondrian parte de uma vanguarda histórica e traz todas estas influências para compor seu trabalho, que é arraigado de uma força sintética racional. Ferrari, por sua vez, não explicita esse caráter procurando estabelecer um contato com o atual a partir das referências locais em que ele estava inserido. Os dois artistas, portanto, se aproximam de maneira evidente quanto ao geometrismo utilizado como recurso formal para compor seus trabalhos. 
Figura 6: Piet Mondrian. Broadway Boogie Woogie, 1942-43

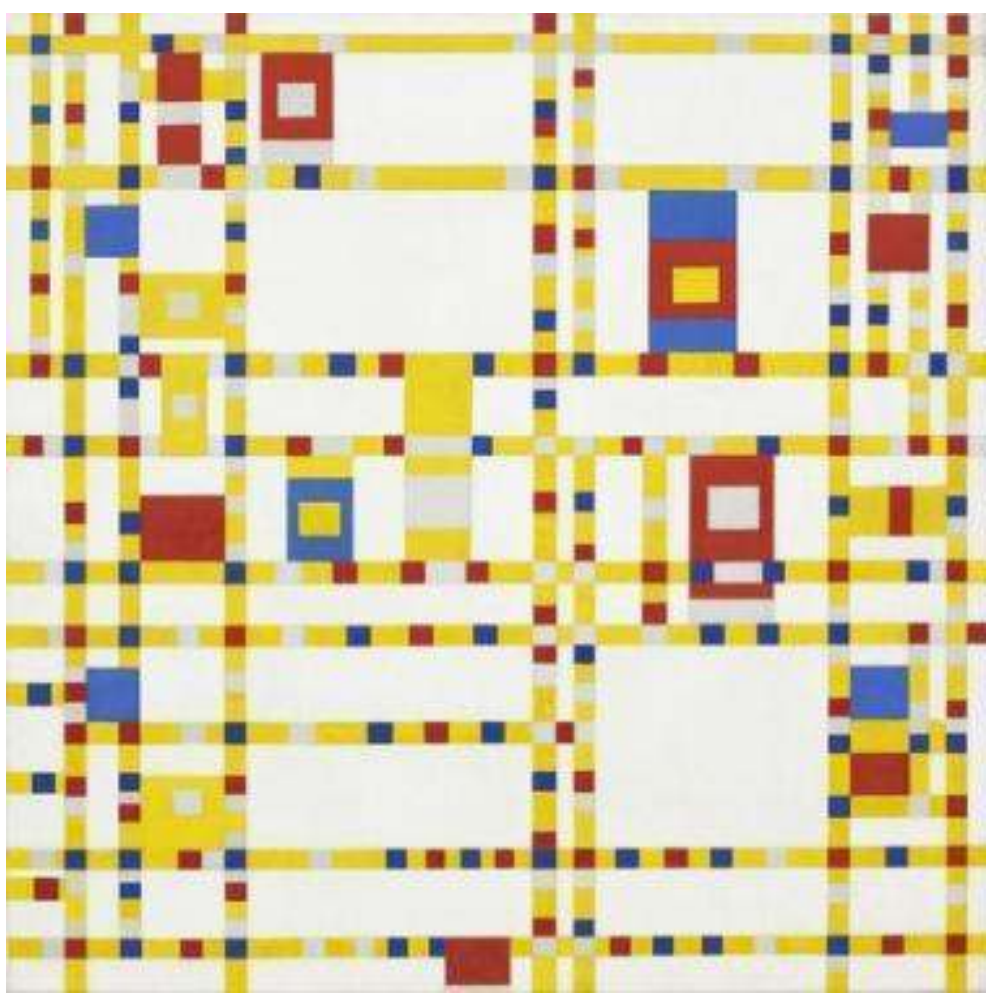

Óleo sobre tela, $127 \times 127 \mathrm{~cm}$. MoMA - Nova York.

Fonte : http://www.moma.org/collection/brow...

Há nos trabalhos dos dois artistas uma alusão clara ao anonimato que a densidade urbana confere aos indivíduos, uma massificação da identidade e da singularidade, onde o que conseguimos absorver são as formas densas compostas por uma geometria clara e perpendicular, que impelem um movimento rítmico e monótono das cidades cheias de vazios, como se observássemos, como voyeurs, a partir de uma vista aérea. 
Figura 7: Piet Mondrian. Composição. 1916

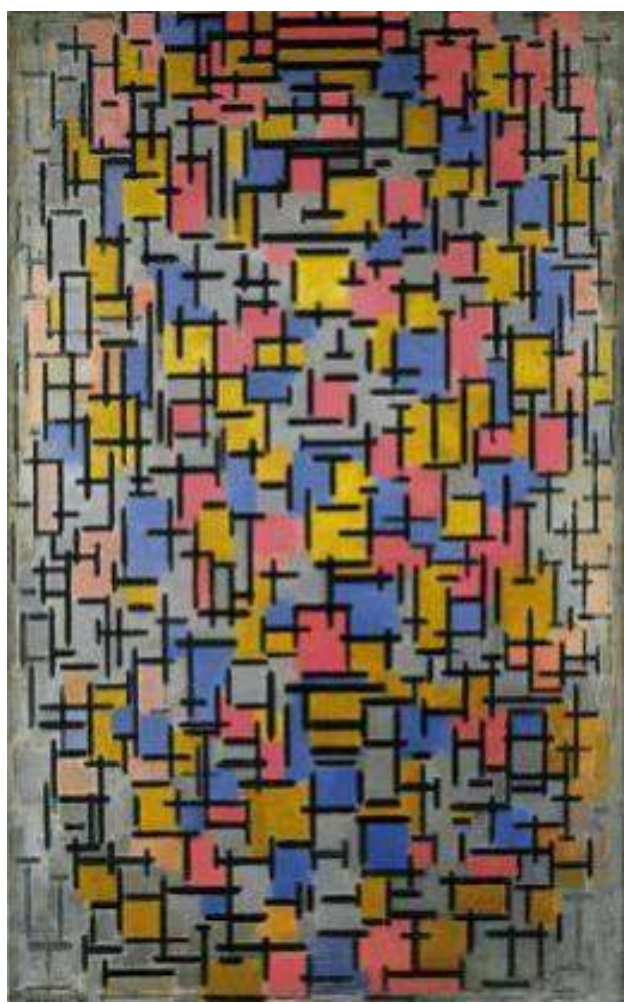

Óleo sobre tela, com madeira, $120 \times 75,6$ cm. Solomon R. Guggenheim Museum, New York.

Fonte : http://www.guggenheim.org/new-york/...

Nos trabalhos de Mondrian, Broadway Boogie Woogie (figura 6) e Composição (figura 7), assim como em Cidade (figura 5), de Ferrari, há uma anulação da linha diagonal, optando-se pelas linhas verticais e horizontais. Esse recurso confere uma proximidade entre o trabalho de ambos os artistas com a poética neoplástica. No primeiro há uma incitação à planta arquitetônica, no segundo, às vias urbanas. Nos dois trabalhos existe a utilização do fracionamento, da planimetria do espaço do trabalho.

Esse fracionamento da linha, que em Cidade e Bairros de Ferrari e em Composição de Mondrian é dada pela secção da própria linha, e que em Broadway BoogieWoogie de Mondrian se faz presente pelas colorações diferentes das linhas,remete à fragmentação dos grandes centros urbanos e também à fragmentação do sujeito moderno e contemporâneo, como se ambos os artistas captassem esse fato precipitadamente. De acordo com Hall :

As identidades culturais estão entrando em colapso [...] Um tipo diferente de mudança estrutural está mudando as sociedades modernas no final do século XX. Isso está fragmentando as paisagens culturais de classe, gênero, sexualidade, etnia, raça e nacionalidade, que no passado, nos tinham fornecido sólidas localizações como indivíduos sociais. Estas transformações estão também mudando nossas identidades pessoais, abalando a ideia que temos de nossos próprios sujeitos integrados. (HALL, 2007 : 9). 


\section{Entre territórios: o cruzamento das fronteiras geográficas} interpessoais, mas também a maneira com que ele desenvolve a sua subjetividade. Quando nos referimos aos artistas, essa maneira singular de se interagir com o mundo é fundamental para o modo de como ele irá desenvolver o seu processo de criação em arte.

Na produção de León Ferrari, há uma modificação singular e específica nos períodos nos quais ele muda de país - ação que é efetuada diversas vezes durante a sua vida. No primeiro momento, quando ele vai para a Itália, ainda sem ter uma prática artística contundente, é um momento de suma importância em sua vida artística, pois é lá que ele "descobrira" a cerâmica, e iniciara primeiramente de modo artesanal e posteriormente como auxiliar de um escultor, suas primeiras produções tridimensionais. Depois, quando vem morar no Brasil, e entra em contato com diversos artistas, encontra um ambiente aberto e profícuo para o desenvolvimento da sua produção artística.

Como já foi mencionado anteriormente, o deslocamento de Ferrari para o Brasil deu-se de modo diferente das demais mudanças que ele fez. Sua mudança para o Brasil ocorreu de maneira relativamente forçosa, devido a questões políticas, já que ele era engajado politicamente e contrário à ditadura que havia sido instaurada em sua pátria.

31 Nesse deslocamento involuntário, Ferrari parece ter encontrado um terreno fértil para um diálogo estreito com outros artistas que de certa forma estavam passando também por uma ditadura (golpe militar de 1964, no Brasil).

32 Neste deslocamento a estrada assume uma dimensão singular, é espaço intervalar entre a chegada e a partida, não é aqui e nem lá, é um entremeio, atua como um lugar de suspensão, um não-lugar, onde o movimento de presentificação do sujeito é sempre transitório, espaço de interstício a permitir que o sujeito neutralize a dimensão espaço/ temporal. É o espaço do sujeito nômade, mesmo que provisoriamente.

\section{A ebulição da criação}

Retomando a questão do movimento inicial do deslocamento exilar, propõem-se como especulação que o artista, por vezes, necessita de uma superfície na qual ele possa deslizar sua capacidade imagética, um espaço profícuo de ebulição criativa. O deslocamento geográfico nesse caso funciona como um dispositivo de ativação de acesso a esse espaço de desdobramento da criação. Elevando a potência criativa e atuando como uma zona profícua de experiência.

Ferrari, assim como alguns outros artistas parece requisitar esse tempo/espaço de transitoriedade, requerer um outro lugar, a experiência do novo, do estrangeirismo, da desestabilização, da desterritorialização, e isso amplia a sua potência de criação.

Talvez essa experiência de deslocamento desperte o artista para uma ampliação de sua percepção ampliando os recursos imagéticos para a sua composição criativa em arte. Pois, a experiência da errância afecta não só a percepção do sujeito, mas também o seu modo de compor com o mundo. 
36 A prática do deslocamento, no entanto, parece propulsar uma potência de criação, quando se trata do campo das artes, e também se estender para demais campos do conhecimento, como as pesquisas acadêmicas.

Entende-se que esta prática de deslocamento é profícua para a expansão não somente da formação da subjetividade do sujeito, como para a ampliação do conhecimento empírico e científico. Portanto, esse "estado de viajante", permite interlocuções necessárias ao desenvolvimento de inúmeros campos, e parece estar sendo cada vez mais compreendida também nesse aspecto.

Ainda ocorrem os exílios, principalmente em países que pertencem à zonas de conflito, na atualmente, nesses casos são em sua maioria ocorridos de forma voluntária, na tentativa dos cidadãos encontrarem um meio onde buscam se reestruturarem enquanto sujeito e a mais qualidade de vida.

No entanto, quando voltamos para a zona artística e acadêmica ativação desse deslocamento atualmente, tem-se dado muitas das vezes, por meio dos seminários de pesquisa, congressos e residências artísticas, que requisitam um deslocamento do sujeito, porém são condensados em uma duração menor. Outros, como os intercâmbios ou as pesquisas de campo, cujo tempo de duração são mais prolongados, requisitam uma fixação, ou uma residência temporária do sujeito, são formas de exercer esse "exílio" e manter latente essa centelha nômade que é tão potente em experiência.

Seja qual for o ímpeto inicial do deslocamento (ou da errância), este suscita sempre uma abertura no campo subjetivo do sujeito, que lança-o para uma possibilidade intrínseca de mudanças, ou, mais densamente devires, a corroborarem com uma fusão entre os movimentos: centrífugo - oriundo das camadas mais internas do indivíduo - e centrípeto - convergente do ambiente externo para o seu interno. $\mathrm{E}$ o artista, que além dos materiais que lhe são necessários para produzir seu trabalho de arte, também utiliza inerentemente como recurso as suas vivências, experiências e percepções do mundo, como componentes ativos em seu processo de criação. Este, tem com as experiências de deslocamento, subsídios ainda mais singulares para o seu ato criativo.

\section{BIBLIOGRAFIA}

AMARAL Aracy, "León Ferrari: os anos paulistas (1976 - c. 1984)", in León Ferrari: retrospectiva. Obras 1954-2006, GIUNTA, Andrea. (ed.), São Paulo, Cosac\&Naify, 2006. p. 51-59.

ARGAN Giulio Carlo, Arte Moderna, São Paulo, Cosac \&Naify, 1992.

CAVENAGHI Airton José, "Niépce: “A invenção que fiz...", in: UEL, DOMÍNIOS DA IMAGEM Londrina, n. 3 ano II. 2008. p. 7-18.

DEMOS T.J., The exiles of Marcel Duchamp, Massachusetts, Cambridge, 2007.

DELEUZE Gilles; GUATTARI Félix, Mil Platôs: capitalismo e esquizofrenia, vol. 4. São Paulo, Editora 34, 1997. 
DELEUZE Gilles; GUATTARI Félix, Mil Platôs : capitalismo e esquizofrenia, vol. 5. São Paulo, Editora 34, 1997.

DEBOIS Philippe, $O$ ato fotográfico e outros ensaios, Campinas/SP, Papirus, 1993.

GIUNTA Andrea, "Cronology", in. León Ferrari: retrospectiva. Obras 1954-2006, GIUNTA Andrea. (ed.), São Paulo, Cosac\&Naify, 2006, p. 355-422.

HALL Stuart, A identidade cultural na pós-modernidade, Rio de Janeiro, DP\&A, 2006.

KLEE Paul, Theorie de l'art moderne, Paris, Denoel, 1985.

KRAUSS Rosalind, "Girds", in October, 9.v., The MIT Press, summer 1979. pp. 50-64. Disponível em : http://www.jstor.org/stable/778321.

MILNER John, Mondrian, New York, Abbeville, 1992.

PÉREZ-ORAMAS Luís, León Ferrari e Mira Schendel : o alfabeto enfurecido,São Paulo, Cosac\&Naify, 2010.

\section{RESUMOS}

Escrever, escrever e desenhar. Escrever sobre as proposições sutis calcadas na sedimentação de um acontecimento subjetivo. Este artigo é uma abordagem investigativa sobre a série intitulada : "Arquitetura da Loucura", de León Ferrari (1920-2013), no momento em que o artista argentino exilou-se no Brasil. Propõe-se, no estudo dessas imagens, uma análise reflexiva sobre as inferências sensíveis do deslocamento geográfico em sua investigação do simbólico, como também, um olhar sobre os dispositivos que o levou a construir uma percepção distinta sobre a "fronteira".

Écrire, écrire et dessiner. Écrire sur les propositions subtiles tirées de la sédimentation d'un événement subjectif. Cet article porte sur la série intitulée : "L'architecture de la folie ", de León Ferrari (1920-2013), durant l'exil de l'artiste argentin au Brésil. On propose une analyse réflexive de ces images, en attirant l'attention sur les conséquences sensibles du déplacement géographique dans sa recherche du symbolique, et sur les dispositifs qui l'ont amené à construire une perception distincte de la « frontière ».

\section{ÍNDICE}

Palavras-chave: León Ferrari, Brasil, heliografia, exílio, ciudad

Mots-clés: León Ferrari, Brésil, héliographie, exil, ville

\section{AUTOR}

\section{CAROLINY PEREIRA}

Doutoranda em Artes Visuais pelo Instituto de Artes da Unicamp, sob orientação do Prof. Dr. Edson do Prado. ceroliny[at]gmail.com 